\title{
Remission of maternal depression and child symptoms among single mothers:
}

\author{
A STAR ${ }^{\star} D$-Child report \\ Ardesheer Talati, Ph.D., \\ Dept. of Psychiatry, Columbia University, 1051 Riverside Drive, Unit 24, New York (NY), 10032 \\ USA
}

Priya J. Wickramaratne, Ph.D.,

Dept. of Psychiatry, Columbia University, 1051 Riverside Drive, Unit 24, New York (NY), 10032 USA

Daniel J. Pilowsky, M.D., M.P.H.,

Dept. of Epidemiology and Psychiatry, Columbia University, New York (NY), USA

Jonathan E. Alpert, M.D., Ph.D.,

Dept. of Psychiatry, Massachusetts General Hospital, Boston (MA), USA

Gabriele Cerda, M.D.,

Dept. of Psychiatry, University of California at San Diego, San Diego (CA), USA

Judy Garber, Ph.D.,

Dept. of Psychology and Human Development, Vanderbilt University, Nashville (TN), USA

Carroll W. Hughes, Ph.D.,

Dept. of Psychiatry, University of Texas Southwestern Medical Center, Dallas (TX), USA

Cheryl A. King, Ph.D.,

Depts. of Psychology and Psychiatry, University of Michigan, Ann Arbor (MI), USA

Erin Malloy, M.D.,

Dept. of Psychiatry, University of North Carolina Medical Center, Chapel Hill (NC), USA
A. Bela Sood,
Dept. of Psychiatry, Virginia Commonwealth University, Richmond (VA), USA

Helen Verdeli, Ph.D.,

Dept. of Psychiatry, Columbia University, 1051 Riverside Drive, Unit 24, New York (NY), 10032

USA. Dept. of Counseling and Clinical Psychology, Teachers College, Columbia University, New York (NY), USA

Madhukar H. Trivedi, M.D.,

Dept. of Psychiatry, University of Texas Southwestern Medical Center, Dallas (TX), USA
A. John Rush, M.D., and
Dept. of Psychiatry, University of Texas Southwestern Medical Center, Dallas (TX), USA
Myrna M. Weissman, Ph.D.
Dept. of Psychiatry, Columbia University, 1051 Riverside Drive, Unit 24, New York (NY), 10032 USA 
Ardesheer Talati: at2071@columbia.edu

\section{Abstract}

Objective-Offspring of depressed parents are at increased risk for depressive and other disorders. We recently found that when depressed mothers reached full remission over 3 months of treatment, a significant improvement in the children's disorders occurred. Since only a third of the mothers remitted, factors related to maternal remission rates, and thereby child outcomes, were important. This report examined the relationship of the presence of a father in the household to maternal depression remission and child outcomes.

Method-Maternal depression was measured using the 17-item Hamilton Rating Scale for Depression $\left(\mathrm{HRSD}_{17}\right)$; social functioning was assessed using the Social Adjustment Scale-Self Report (SAS-SR). Children (age 7-17) were assessed independently, blind to maternal outcome, using the Schedule for Affective Disorders and Schizophrenia for School-Age Children (K-SADSPL) and the Child Global Assessment Scale (C-GAS).

Results-Single mothers $(n=50)$, as compared to those in two-parent households $(n=61)$, were more likely to discontinue treatment ( $31 \%$ vs. $16 \%, P=0.04)$, and less likely to remit if they remained in treatment ( $20 \%$ vs. $43 \%, P=0.013)$. These differences remained significant after adjusting for socioeconomic status and potential confounders, but were partially explained by the mother's pre-treatment social functioning. The reduction in child diagnoses following maternal remission was greater in two-parent than in single-parent households, although a formal test of interaction between the odds ratios was not significant.

Conclusion-Single depressed mothers are more likely to drop out of treatment, and less likely to reach remission if they stay in treatment. This high-risk group requires vigorous treatment approaches.

\section{Keywords}

fathers; single mothers; depression; remission; social functioning; STAR*D

\section{Introduction}

Major depressive disorder (MDD) is a highly prevalent, impairing, and often familial psychiatric disorder. Children of depressed parents are themselves at an over twofold increased risk for MDD as well as for other psychiatric disorders [16,19,25,46]. Until recently, however, it was unclear whether reducing the burden of parental depression by successful treatment could alleviate the child's psychopathology. The "Sequenced Treatment Alternatives to Relieve Depression" (STAR*D) study [17,33] provided a unique opportunity to examine the impact of maternal depression remission on their children. STAR*D mothers and their children (aged 7-17) were invited to participate in the STAR*DChild study [31]. The children were not provided any treatment by the study team, but were followed along with their mothers at 3-month intervals to determine whether improvement in maternal depression was associated with decreased psychiatric symptoms or improved functioning of offspring.

At entry into STAR*D Child (i.e., prior to treatment), all mothers were clinically depressed (72\% were severely depressed), and a third of their children (34\%) met criteria for a current diagnosis of a psychiatric disorder (most prominently, disruptive behavior, anxiety, and depressive disorders) [31]. Three months after initiation of maternal treatment, $34 \%$ of the mothers had achieved remission. The children of mothers who remitted also had significantly fewer psychiatric symptoms and fewer diagnoses than children of mothers who did not remit [44]. Because only a third of the mothers remitted within the first 3 months of 
treatment—a finding consistent with other clinical trials of depressed women (e.g., [37])— we were interested in factors that were positively linked with maternal remission rates, and thereby with child outcomes.

In this study, we examined the relation of having a father living in the household to mothers' and children's outcomes. We chose this focus because single mothers are more socially isolated, have fewer social networks, experience more stressful life events, and are at increased risk for depressive, anxiety, and substance use disorders as compared to married mothers $[8,9,24,40,41]$. These problems negatively impact their parental role, with single mothers having greater parenting stress and conflict with their children, as well as a greater propensity for child abuse [27,29]. Compared to children raised by two parents, children raised by single mothers also have greater internalizing and externalizing problems, and are more likely to suffer both social and academic impairment [20,29]. Although some of these differences may be attributable to income, they persist after accounting for socioeconomic proxies $[7,15]$. These findings suggest that fathers, and perhaps other adults serving a second parental role, play an important and possibly protective role in maternal and child functioning.

This report examined the relation of fathers in the household to maternal outcomes 3 months after initiation of the mother's treatment for depression. We tested whether mothers in twoparent households were more likely to remit within the first 3 months of treatment than single mothers, and if so, whether differences in socioeconomic status or social functioning could explain these differential remission rates. We also explored whether children in twoparent households would be more likely to benefit from their mother's remission than children in single-parent households.

\section{Methods}

\section{Study design}

STAR*D Child was an ancillary study based on STAR*D, a multi-site trial detailed elsewhere $[17,33,35,38]$. STAR $* \mathrm{D}$-Child was designed to test the relation of a remission of maternal depression to children's psychiatric symptoms and social functioning. Mothers in STAR *D were invited to participate with one of their children (chosen randomly). The STAR*D-Child protocol was reviewed and approved by the Institutional Review Boards at each participating site, and written informed consent and assent were obtained respectively from mothers and children. One hundred and seventy four mothers recruited by STAR*D met eligibility criteria to participate in STAR*D Child [23]. One hundred and fifty one mother-child pairs (87\%) consented to participate and enrolled in the study; of these, One hundred and fourteen $(75 \%)$ remained in the study at 3 months.

\section{Classification of mother-child pairs}

Mother-child pairs were dichotomized based on whether or not there was a full-time resident male in the household. This classification was adopted as we believed it would serve as a more functionally relevant proxy of the father's impact on the mothers and children than legal marital status. Sixty one of One hundred and fourteen (54\%) motherchild pairs lived with a full-time resident male in the household (all of whom happened to be the biological father of at least one child in the household, and forty were the biological father of the participating child). We designated these 61 mother-child pairs as two-parent households. Fifty (44\%) mother -child pairs reported no resident male of any kind in the household, and were designated as single-mother households. Three mother-child pairs could not be cleanly categorized on the above criteria. In two cases, the mother had a current boyfriend (who was not the father of any of her children) whose status of residence in the 
household was unknown, and in one case, the participating child shared equal residence between the mother and the biological father and stepmother. These three mother-child pairs were excluded a priori (subsequent analyses however found the main results to be robust to their inclusion in either group). Among the mothers in two-parent households, $87 \%$ were currently legally married to the resident male. Among the single mothers, $36 \%$ had never been married, and $64 \%$ had been previously married (none were currently married).

\section{Assessments}

Mothers-Mothers received a comprehensive battery of demographic, psychosocial, and clinical assessments as part of the adult STAR*D study [17,33]. The mother's initial diagnosis of MDD was established by clinical interview and confirmed using a symptom checklist based on DSM-IV [23]. The severity of depressive symptoms was estimated using the 17-item clinician-rated Hamilton Rating Scale for Depression (HRSD 17$)$. Remission was defined as a HRSD 17 Score $\leq 7$ [18]. Maternal social functioning was assessed using the Social Adjustment Scale-Self-report (SAS-SR) [43], a reliable and widely used instrument that assesses six major areas of social functioning: work-role (which assesses employment, housework and student work), social and leisure activities, relationships with extended family, role as a partner in primary relationship, parental role, and role within the family unit. STAR*D Child assessed all domains except (due to time constraints) "relationships with extended family." There are a total of 54 questions, each scored on a 5-point scale, with higher scores indicating poorer functioning. Scores for each role are calculated by averaging the scores for all relevant items.

Thirty seven mothers dropped out of the study within the first 3 months, and had no clinician $\mathrm{HRSD}_{17}$ assessments beyond their baseline evaluation. Ten of these mothers (four single mothers, and six from two-parent households) dropped out within the first 14 days. For the 27 mothers who stayed in the study beyond the first 2 weeks, intermediate remission and response outcomes were generated by converting the mothers' self-reports of depressive symptoms (assessed bi-weekly on the 16-item Quick Inventory for Depressive Symptomatology self-report [QIDS-SR ${ }_{16}$ ]; [33] at the last available assessment into $\mathrm{HRSD}_{17}$ scores using an item response theory analysis of the relation between the $\mathrm{HRSD}_{17}$ and the QIDS-SR 16 scales, a method previously used by $\mathrm{STAR}_{16} \mathrm{D}[32,39]$.

Children-Children's psychiatric disorders at baseline and at the 3-month evaluation were obtained by separate direct interviews of mothers and of children using the Schedule for Affective Disorders and Schizophrenia for School-Age Children-Present and Lifetime Version (K-SADS-PL) [23], a widely used valid and reliable diagnostic assessment which generates DSM-IV diagnoses. Clinicians assessing child outcomes were independent of, and masked to, the clinicians' assessments of maternal depression. The child's global functioning was assessed using the clinician-rated Child Global Assessment Scale (C-GAS) [36], as previously described [31].

Fathers-Demographic information on fathers was obtained from the mother at the baseline interview. Paternal lifetime psychiatric history was ascertained using the Family History Screen, with the mother as the respondent. This questionnaire assesses 15 psychiatric disorders and suicidal behavior in self and first-degree relatives, and has been demonstrated to have good validity, reliability, and agreement with best-estimate diagnoses [45]. Information was only available for the biological fathers of the child participating in STAR*D-Child, and results should therefore be interpreted accordingly. 


\section{Statistical analyses}

Differences in maternal and child variables by the father's status in the household were initially examined using Chi-Square tests for categorical variables (or Fisher's Exact test, if one or more cell had an expected cell count of less than 5), and $t$-tests for continuous variables. The relation between fathers' presence and maternal remission was tested in multivariate logistic regression models, with maternal remission as the categorical outcome variable, father's presence/absence in the house as the categorical independent variable, and other covariates of interest included as specified. The effects of the fathers on the association between maternal remission and child outcomes were analyzed using a repeated measures analysis with binary response data, using Generalized Estimating Equation (GEE) methods $[1,44]$. Changes in rates of child diagnoses from baseline to 3 months as a function of mother's remission status were first analyzed separately for children with and without fathers. The outcome measures in each model were the rates of diagnoses at each of the two time points (baseline, 3 months), and the independent variables were time, mother's remission, and a time x mother's remission interaction term. Analyses were adjusted for age and gender of child, severity of maternal baseline depressive symptoms, and annual household income. The time $x$ mother's remission term formally tested whether changes in rates of childhood diagnoses over 3 months differed significantly between remitted and unremitted mothers for each group. In the final analysis comprising all mother-child pairs, a 3-way interaction term, time $x$ mother's remission $x$ father status was included to formally test the effect of moderation.

\section{Results}

Of the 151 mother-child pairs who entered STAR*D Child, 114 (75\%) completed the follow-up assessment at 3 months. Single mothers were more likely to dropout of the study as compared to mothers from two-parent households ( $31 \%$ vs. $16 \%, P=0.04)$. Mother-male child pairs were also more likely to dropout of the study as compared to mother-female child pairs (33\% vs. $15 \%, P=0.02)$. There were no significant differences in severity or chronicity of maternal depression, comorbid symptoms, or adherence to treatment, between participants and dropouts. This report focuses on the 111 mother-child pairs who remained in the study at 3 months and were classifiable as living in either a two-parent $(n=61)$ or a single-mother $(n=50)$ household (see Methods).

\section{Mother-child assessments at baseline}

Maternal and child baseline demographic and clinical characteristics are shown in Table 1. Single mothers, as compared to those in dual-parent households, were of lower socioeconomic status (they were more likely to have annual household incomes below $\$ 15,000$, less likely to hold a college degree, and more likely to be on welfare), and were more severely depressed. Mothers did not differ on measures of depression chronicity (i.e., number of MDEs, length of current episode, age at first onset, or years at risk). Single mothers were also more likely to have obsessive-compulsive disorder, panic disorder, and greater impairment in work and social/leisure functioning. Treatment parameters (psychiatric versus primary care setting, medication dose, and adherence to medication) did not vary between groups. Children of single mothers tended to have lower global functioning than those of two-parent households (Table 1).

\section{Maternal remission and response to treatment}

Following 3 months of treatment in STAR*D, 43\% (26/61) of mothers living in dual-parent households achieved full remission (i.e., a $\mathrm{HRSD}_{17}$ Score $\leq 7$ ) as compared to only $20 \%$ (10/50) of single mothers (OR: 2.97, $P=0.013$ ). The overall profile for these two groups of mothers is illustrated in Fig. 1. For example, mothers in two-parent households were more 
than twice as likely to show a $75 \%$ or greater reduction in baseline symptom severity than single mothers ( $31 \%$ vs. $15 \%$ ); conversely, single mothers were more than twice as likely to experience a worsening of symptoms (13\% vs. 5\%). A successful response (defined a priori as $\geq 50 \%$ reduction in baseline symptoms) was $52 \%$ for mothers living in dual-parent households and $28 \%$ for single mothers $(\mathrm{OR}=2.90, P=0.009)$. When imputed data on partial outcomes for mothers who dropped out of the study were included in the analysis (see Methods), findings were unchanged. Mothers in two parent households remained more than twice as likely both to remit ( $\mathrm{AOR}=2.99, P=0.005)$ and to respond (AOR $=2.42, P=$ $0.01)$ to treatment than single-mothers.

The association between fathers' presence in the household and maternal remission remained significant after adjusting for the mother's age, severity of depression at baseline, co-morbid anxiety, physical health and health related quality of life, number of children, total number of persons living in the household, receipt of primary versus psychiatric care, and adherence to treatment protocol (data available upon request). Importantly, the above association also remained significant after adjusting for multiple socioeconomic indicators including annual household income, maternal education, employment, and receipt of public assistance. Even after inclusion of all of the above socioeconomic indicators in a single model, the father's presence in the household was the strongest single predictor of maternal remission, with mothers in two-parent households three times as likely to remit as single mothers $(\mathrm{AOR}=3.23$ [95\% CI: $1.23,8.51], P=0.017)]$.

Since the association between the father's presence and maternal remission was not accounted for by income or other socioeconomic indicators, we examined whether differences in mothers' social functioning could explain why the single mothers were less likely to remit. There were no significant changes in the mother's social functioning (assessed by the SAS-SR) over the course of the 3 months. However, the mother's baseline functioning in the social-leisure domain was significantly associated both with whether or not there was a father present in the household (mean SAS-SR score difference, $0.45 ; P<$ $0.001)$, and with whether or not the mother remitted from depression $(0.55, P<0.001)$. Furthermore, the association between the father's presence in the household and the mother's remission $(\mathrm{OR}=2.97[1.25,7.01], P=0.01)$ was substantially reduced (AOR $=1.9$ $[0.78,4.96], P=0.17$ ) (a 36\% decrease) after including the mother's social-leisure functioning (AOR $=0.34$ [0.17. 0.70], $P=0.003$ ) as a covariate in the model (Table 2). These findings were unchanged after further adjustments for annual household income, and were not observed for any other domains of the mother's social functioning (data available upon request).

Finally, we tested whether demographic or clinical differences between the fathers who lived in the household versus those who did not were related to maternal outcomes. Paternal demographic and clinical characteristics are shown in Table 3, as reported by the mother for the biological father of the child participating in the study. The fathers who did not live in the household were more likely to be non-white, less likely to hold a college degree, and had significantly higher rates of substance use and incarceration, as compared to fathers living with the mother-child pair. However, the association between the father's presence in the household and maternal remission remained significant after adjusting for these differences (data available upon request).

\section{Relation among fathers, maternal remission and child outcomes}

We explored whether the association between the mothers' remissions and the children's outcomes varied based on the presence/absence of a father in the household. As shown in Table 4, when examined separately in single-parent and two-parent households, the mother's remission only resulted in a significant reduction in the children's psychiatric diagnoses in 
two-parent households. Specifically, there was a $15.4 \%$ decrease in diagnosis rates among children if the mother remitted, and a 5.7\% increase if the mother did not remit. In single parent households, there was no change in the children's diagnoses if the mother remitted, and a $2.6 \%$ increase if the mother did not remit. However, an interaction term to formally test whether the odds ratios for mothers in single-parent and two-parent households were different was not significant after adjusting for the child's age, gender and household income $(P=0.10)$.

\section{Discussion}

We showed that single depressed mothers, as compared to those from two-parent households, have poorer treatment outcomes. Specifically, single mothers were twice as likely to drop out of treatment, and were more than three times less likely to remit within the first 3 months even if they remained in treatment, suggesting that they are resistant not only to the treatment but also somehow to being in treatment. Importantly, although the single mothers had significantly lower income and education levels (consistent with the body of literature showing an association between poverty and depression [8]), their lower rates of remission held after adjusting for multiple socio-economic confounders. Thus, single mothers did not fare worse simply because they were poorer. In fact, subsequent examination revealed that single mothers had significantly impaired social-leisure functioning and that this impairment partially explained why they were less likely to remit. A number of possible mechanisms might account for this. For example, the presence of a male companion might have provided social support that enabled the mothers to function better and to respond better when undergoing treatment for depression. Conversely, low social functioning could have played a role in single depressed women not having a partner, and consequently not having the social support needed to buffer stressors that may have precipitated depressive episodes, and to stay in treatment. Or instead of either unidirectional pathway, some under-lying vulnerability trait(s) in the mothers could have commonly predisposed them to all of the observed outcomes. One such example that resonates with our observations is the mother's interpersonal attachment style. Attachment theory posits that types of interpersonal attachment, which range from secure to insecure, form early in childhood experiences, are internalized, and become relatively stable by early adulthood across different interactions [2,3,5]. Secure attachment styles are associated with comfortable dependence on others in relationships. Insecure styles, in contrast, are characterized by diminished self-esteem, discomfort with trusting or relying on others (relevantly, especially during times of distress or illness), and fear of intimacy [2,3]. Insecure attachment styles may be related to mothers having lower social functioning (the SAS-SR domain assesses similar constructs such as the extent of engagement interest and neglect within social interactions), with being unable- or unwilling- to finding a partner, with greater affective psychopathology [4], and with poorer parent-child interactions and parenting, and may explain why in our study children of single mothers who remitted tended to have worse outcomes than the children of remitting mothers in two-parent households.

Finally, there is also intriguing evidence in both primary and psychiatric medicine that patients with insecure attachment exhibit lower treatment adherence and poorer treatment outcome, and that this may be mediated by poorer interactions with their health care providers $[11,12]$. Although the STAR*D trial may not be representative of regular patientprovider interactions, such factors could still plausibly account for the higher drop out rates among single mothers in our study. For instance, the single mothers may have been less communicative with or trusting of the STAR*D clinicians to provide care-a hallmark of dismissive attachment style [21] — and thereby less invested in adhering to the treatment protocol or remaining enrolled in the study. 
Our observation that the impact of the fathers is partially explained by the mothers' social functioning is also important from an interventional perspective, as social functioning is a more therapeutically malleable target than marital or partnership status. Enrolling lowfunctioning and single depressed mothers in individual or group psychotherapies that target problems in social functioning by providing case management to deal with practical issues that occur in single-parent households may increase the chances of a positive outcome. This hypothesis is consonant with the studies of Miranda et al. [28] and Lipman and Boyle [26] who found that single or young minority women, when offered guideline-consistent care including case management and support, had better outcomes than with standard treatment (although Miranda's study did not separate out single parents, $44 \%$ were unmarried). Furthermore, although STAR*D was not designed to study single motherhood per se, the overall demographics and lifetime clinical profiles of the single mothers in our study are congruent with those found in previous epidemiologic studies of single-parent households [42]. Because the design did not target single mothers in particular, however, the recruited sample encompassed women with a wide range of SES (e.g., of the full sample of 151 mothers at baseline, $26 \%$ were below the poverty line, and $19 \%$ had incomes above $\$ 60,000)$, race, geographical distribution, and treatment setting. This variation may help explain why previous interventions with low-income minority mothers (e.g., Miranda et al. [28]) have reported difficulty in engaging patients in treatment. By being restricted to lowerincome, minority, or single mothers, these studies may have in essence been capturing primarily a group at highest risk for non-remission.

One final note about the mothers' treatment: although the STAR*D treatment design included non-pharmacological options, all mothers represented in this report were on pharmacotherapy only (most were still on citalopram, the initial treatment in the STAR*D protocol) [33]. Yet, their response to treatment was modulated by non-pharmacological variables such as social functioning. This finding is consistent with the growing body of evidence showing that psychopathological vulnerability is conferred by an interaction of multiple genetic and environmental factors [10], and suggests that remission and recovery may be similarly dependent on such interactions.

The relation of fathers to child outcomes was more complex. Even though the association between maternal depression remission and improvement in children's diagnoses was only found in two-parent families, this should be interpreted cautiously because a formal test of the interaction did not find the differences in odds ratios to reach statistical significance. If children in two-parent households indeed have better outcomes following their mother's remission, this then suggests that having a father present may have a beneficial impact on child outcomes. This impact may be indirect, via the father facilitating the mother's improvement, which in turn may have affected the children, or direct, that is fathers interacting with children in a manner that may have buffered the impact of the mother's depression on her children. Importantly, the fathers who did not live in the household also had higher lifetime rates of substance use and incarceration. Their children, who themselves tended to have higher levels of externalizing disorders, may not only have lacked the positive environment conferred by a stable paternal presence, but also may have been further exposed to the negative impact of their father's externalizing psychopathology. It also is possible that these children's externalizing tendencies were the result of genes shared by them and their fathers or by the increased genetic loading from having two parents with psychopathology.

The literature dealing with fathers in general, and paternal depression in particular, is limited compared to that of mothers partly because depression is more prevalent in women, mothers are more likely to come for treatment, and following separation or divorce, most children live with their mothers [30]. Despite these limitations, there is an emerging literature on the 
relation of paternal psychopathology to childhood disorders and development (see reviews by Connell and Goodman [13], and Kane and Garber [22]). Some studies have found that children who have two depressed parents are more vulnerable than children with a depressed mother only $[6,14]$. In STAR*D-Child, fathers were not assessed directly. Information on their psychiatric history, which was obtained through the mothers, was thus limited and vulnerable to maternal reporting bias. We can not comprehensively address the role of paternal psychopathology in relation to maternal and child outcomes, and further studies with direct interviews of fathers (both biological and non-biological, resident and nonresident) alongside mothers and children are warranted.

Several additional limitations should be acknowledged. First, STAR*D Child examined only treatment-seeking depressed mothers and their children. It is unclear whether the findings would generalize to less severely depressed or to non-treatment seeking mothers, or to depressed fathers. Second, even though the father's presence in the household was associated with maternal remission, we cannot rule out that if we had studied an alternative cohabiting adult — for e.g., a grandparent or friend - that we would not have found similar results. This is an intriguing hypothesis, and if future studies can replicate these effects with other non-paternal adults, this would have important social implications for intervention programs with single mothers. In either case, the current findings underscore the wellknown difficulties for depressed mothers of raising children alone. Third, only a small number of possible explanatory factors were considered, as STAR*D was an effectiveness study, and nonessential measures were kept to a minimum. As detailed earlier, it is possible that other unmeasured characteristics of the mothers contributed to their likelihood of having a significant male relationship, their chances of remission from depression, as well as the level of their children's psychopathology. A related limitation is that the findings of the present study are correlational. Given that it is not possible to randomly assign families to the presence or absence of a male in the house, such other variables cannot be ruled out, and thus, causal conclusions are not warranted at this time. Finally, our characterization of mother-child pairs does not account for past living circumstances, or for possible variation in involvement in the child's life of fathers who were not part of the household.

\section{Conclusions}

Despite these limitations, this study holds significant clinical and public health implications. We have previously shown that when mothers achieve remission of their depression with medication, there is a concomitant positive change in their children as well. The present study showed that single depressed mothers did not fare as well as did those who had a residential male partner, and remission of their depression did not appear to be linked with significant change in their children. We have therefore identified a high-risk group of singleparent, socially impaired, depressed mothers, where the outcomes for the mothers and their children are less favorable, and who may require more targeted therapeutic strategies.

\section{Acknowledgments}

This study was supported by NIMH grant \# R01MH063852 (MM Weissman, PI) and by an NIMH contract (\#N01 MH90003) (A. John Rush, PI). Dr. Garber was supported in part by an Independent Scientist Award from NIMH (K02 MH66249). The content of this publication does not necessarily reflect the views or policies of the Department of Health and Human Services, nor does mention of trade names, commercial products, or organizations imply endorsement by the US Government. Funding sources played no role in the design and conduct of the study; collection, management, analysis and interpretation of the data; and preparation, review, or approval of the manuscript. We are grateful to the seven participating STAR*D Regional Centers: Massachusetts General Hospital, Boston, MA, Andrew Nierenberg, M.D.; University of California, San Diego, CA,: Sid Zisook, M.D., University of Michigan, Ann Arbor, MI, Elizabeth Young, M.D., University of North Carolina, Chapel Hill, NC, Bradley Gaynes, M.D., M.P.H.; University of Texas Southwestern Medical Center, Dallas, TX, Mustafa Husain, M.D., Vanderbilt University, Nashville, TN, Steven Hollon, Ph.D.; Virginia Commonwealth University, Richmond, VA, Susan Kornstein, M.D. 


\section{References}

1. Agresti, A. Categorical data analysis. 2. John Wiley \& Sons, Inc; New York: 2002. p. 120

2. Ainsworth, MS.; Blehar, MC.; Waters, E.; Wall, S. Patters of attachment: a psychological study of the strange situation. Erlbaum; Hillsdale: 1978.

3. Bartholomew K, Horowitz LM. Attachment styles among young adults: a test of a four-category model. J Pers Soc Psychol 1991;61(2):226-244. [PubMed: 1920064]

4. Bifulco A, Kwon J, Jacobs C, Moran PM, Bunn A, Beer N. Adult attachment style as mediator between childhood neglect/abuse and adult depression and anxiety. Soc Psychiatry Psychiatr Epidemiol 2006;41(10):796-805. [PubMed: 16871369]

5. Bowlby, J. Attachment and loss, vol. II: separation: anxiety and anger. Basic Book; New York: 1973.

6. Brennan PA, Hammen C, Katz AR, Le Brocque RM. Maternal depression, paternal psychopathology, and adolescent diagnostic outcomes. J Consult Clin Psychol 2002;70(5):10751085. [PubMed: 12362958]

7. Brooks-Gunn J, Duncan GJ. The effects of poverty on children. Future Child 1997;7(2):55-71. Review. [PubMed: 9299837]

8. Brown GW, Moran PM. Single mothers, poverty and depression. Psychol Med 1997;27(1):21-33. [PubMed: 9122302]

9. Cairney J, Boyle M, Offord DR, Racine Y. Stress, social support and depression in single and married mothers. Soc Psychiatry Psychiatr Epidemiol 2003;38(8):442-449. [PubMed: 12910340]

10. Caspi A, Moffitt TE. Gene-environment interactions in psychiatry: joining forces with neuroscience. Nat Rev Neurosci 2006;7(7):583-590. [PubMed: 16791147]

11. Ciechanowski P, Russo J, Katon W, Simon G, Ludman E, Von Korff M, Young B, Lin E. Where is the patient? The association of psychosocial factors and missed primary care appointments in patients with diabetes. Gen Hosp Psychiatry 2006;28(1):9-17. [PubMed: 16377360]

12. Ciechanowski P, Russo J, Katon W, Von Korff M, Ludman E, Lin E, Simon G, Bush T. Influence of patient attachment style on self-care and outcomes in diabetes. Psychosom Med 2004;66(5): 720-728. [PubMed: 15385697]

13. Connell AM, Goodman SH. The association between psychopathology in fathers versus mothers and children's internalizing and externalizing behavior problems. Psychol Bull 2002;128:746-773. [PubMed: 12206193]

14. Dierker LC, Merikangas KR, Szatmari P. Influence of parental concordance for psychiatric disorders on psychopathology in offspring. J Am Acad Child Adolesc Psychiatry 1999;38(3):280288. [PubMed: 10087689]

15. Dodge KA, Pettit GS, Bates JE. Socialization mediators of the relation between socioeconomic status and child conduct problems. Child Dev 1994;65:649-665. [PubMed: 8013245]

16. Downey G, Coyne JC. Children of depressed parents: an integrative review. Psychol Bull 1990;108:50-76. [PubMed: 2200073]

17. Fava M, Rush AJ, Trivedi MH, Nierenberg AA, Thase ME, Sackeim HA, Quitkin FM, Wisniewski S, Lavori PW, Rosenbaum JF, Kupfer DJ. Background and rationale for the sequenced treatment alternatives to relieve depression (STAR*D) study. Psychiatr Clin North Am 2003;26:457-494. [PubMed: 12778843]

18. Hamilton M. A rating scale for depression. J Neurol Neurosurg Psychiatry 1960;23:56-62. [PubMed: 14399272]

19. Hammen C, Burge D, Burney E, Adrian C. Longitudinal study of diagnoses in children of women with unipolar and bipolar affective disorder. Arch Gen Psychiatry 1990;47:1112-1117. [PubMed: 2244796]

20. Jablonska B, Lindberg L. Risk behaviours, victimisation and mental distress among adolescents in different family structures. Soc Psychiatry Psychiatr Epidemiol. 2007 (Epub ahead of print).

21. Kafetsios K, Nezlek JB. Attachment styles in everyday social interaction. Eur J Soc Psychol 2002;32:719-735. 
22. Kane P, Garber J. The relations among depression in fathers, children's psychopathology, and father-child conflict: a meta-analysis. Clin Psychol Rev 2004;24(3):339-360. [PubMed: 15245835]

23. Kaufman J, Birmaher B, Brent D, Rao U, Flynn C, Moreci P, Williamson D, Ryan N. Schedule for affective disorders and schizophrenia for school age children present and lifetime version (KSADS-PL): initial reliability and validity data. J Am Acad Child Adolesc Psychiatry 1997;36:980988. [PubMed: 9204677]

24. Kilbourne AM, McCarthy JF, Post EP, Welsh D, Blow FC. Social support among veterans with serious mental illness. Soc Psychiatry Psychiatr Epidemiol. 2007 (Epub ahead of print).

25. Lieb R, Isensee B, Hofler M, Pfister H, Wittchen HU. Parental major depression and the risk of depression and other mental disorders in offspring. Arch Gen Psychiatry 2002;59:365-374. [PubMed: 11926937]

26. Lipman EL, Boyle MH. Social support and education groups for single mothers: a randomized controlled trial of a community-based program. CMAJ 2005;173(12):1451-1456. [PubMed: 16293780]

27. Martins C, Gaffan EA. Effects of early maternal depression on patterns of infant-mother attachment: a meta-analytic investigation. J Child Psychol Psychiatry 2000;41(6):737-746. [PubMed: 11039686]

28. Miranda J, Chung JY, Green BL, Krupnick J, Siddique J, Revicki DA, Belin T. Treating depression in predominantly low-income young minority women: a randomized controlled trial. JAMA 2003;290(1):57-65. [PubMed: 12837712]

29. Olson SL, Ceballo R, Park C. Early problem behavior among children from low-income, motherheaded families: a multiple risk perspective. J Clin Child Adolesc Psychol 2002;31(4):419-430. [PubMed: 12402562]

30. Phares V, Compas BE. The role of fathers in child and adolescent psychopathology: make room for daddy. Psychol Bull 1992;111(3):387-412. [PubMed: 1594718]

31. Pilowsky DJ, Wickramaratne PJ, Rush AJ, Hughes CW, Garber J, Malloy E, King CA, Cerda G, Sood AB, Alpert JE, Wisniewski SR, Trivedi MH, Talati A, Carlson MM, Liu HH, Fava M, Weissman MM. Children of currently depressed mothers: a STAR*D ancillary study. J Clin Psychiatry 2006;67(1):126-136. [PubMed: 16426099]

32. Rush AJ, Bernstein IH, Trivedi MH, Carmody TJ, Wisniewski S, Mundt JC, Shores-Wilson K, Biggs MM, Woo A, Nierenberg AA, Fava M. An evaluation of the quick inventory of depressive symptomatology and the hamilton rating scale for depression: a sequenced treatment alternatives to relieve depression trial report. Biol Psychiatry 2006;59(6):493-501. [PubMed: 16199008]

33. Rush AJ, Fava M, Wisniewski SR, Lavori PW, Trivedi MH, Sackeim HA, Thase ME, Nierenberg AA, Quitkin FM, Kashner TM, Kupfer DJ, Rosenbaum JF, Alpert J, Stewart JW, McGrath PJ, Biggs MM, Shores-Wilson K, Lebowitz BD, Ritz L, Niederehe G. Sequenced treatment alternatives to relieve depression $\left(\mathrm{STAR}^{*} \mathrm{D}\right)$ ): rationale and design. Control Clin Trials 2004;25:119-142. [PubMed: 15061154]

34. Rush AJ, Trivedi MH, Ibrahim HM, Carmody TJ, Arnow B, Klein DN, Markowitz JC, Ninan PT, Kornstein S, Manber R, Thase ME, Kocsis JH, Keller MB. The 16-item quick inventory of depressive symptomatology (QIDS), clinician rating (QIDS-C), and self-report (QIDS-SR): a psychometric evaluation in patients with chronic major depression. Biol Psychiatry 2003;54(5): 573-583. [PubMed: 12946886]

35. Rush AJ, Trivedi MH, Wisniewski SR, Stewart JW, Nierenberg AA, Thase ME, Ritz L, Biggs MM, Warden D, Luther JF, Shores-Wilson K, Niederehe G, Fava M. Bupropion-SR, sertraline, or venlafaxine-XR after failure of SSRIs for depression. N Engl J Med 2006;354(12):1231-1242. [PubMed: 16554525]

36. Shaffer D, Gould MS, Brasic J, Ambrosini P, Fisher P, Bird H, Aluwahlia S. A children's global assessment scale (CGAS). Arch Gen Psychiatry 1983;40:228-231.

37. Thase ME, Entsuah AR, Rudolph R. Remission rates during treatment with venlafaxine or selective serotonin reuptake inhibitors. Br J Psychiatry 2001;78:234-241. [PubMed: 11230034] 
38. Trivedi MH, Fava M, Wisniewski SR, Thase ME, Quitkin F, Warden D, Ritz L, Nierenberg AA, Lebowitz BD, Biggs MM, Luther JF, Shores-Wilson K, Rush AJ. Medication augmentation after the failure of SSRIs for depression. N Engl J Med 2006;354(12):1243-1252. [PubMed: 16554526]

39. Trivedi MH, Rush AJ, Wisniewski SR, Nierenberg AA, Warden D, Ritz L, Norquist G, Howland RH, Lebowitz B, McGrath PJ, Shores-Wilson K, Biggs MM, Balasubramani GK, Fava M. STAR*D Study Team. Evaluation of outcomes with citalopram for depression using measurement-based care in STAR*D: implications for clinical practice. Am J Psychiatry 2006;163(1):28-40. [PubMed: 16390886]

40. Wang JL. The difference between single and married mothers in the 12-month prevalence of major depressive syndrome, associated factors and mental health service utilization. Soc Psychiatry Psychiatr Epidemiol 2004;39(1):26-32. [PubMed: 15022043]

41. Weinraub M, Wolf BM. Effects of stress and social supports on mother-child interactions in single- and two-parent families. Child Dev 1983;54(5):1297-1311. Review. [PubMed: 6354635]

42. Weissman MM, Leaf PJ, Bruce ML. Single parent women. A community study. Soc Psychiatry 1987;22(1):29-36. [PubMed: 3563621]

43. Weissman MM, Olfson M, Gameroff MJ, Feder A, Fuentes M. A comparison of three scales for assessing social functioning in primary care. Am J Psychiatry 2001;158(3):460-466. [PubMed: 11229989]

44. Weissman MM, Pilowsky DJ, Wickramaratne PJ, Talati A, Wisniewski SR, Fava M, Hughes CW, Garber J, Malloy E, King CA, Cerda G, Sood AB, Alpert JE, Trivedi MH, Rush AJ. STAR*DChild Team. Remissions in maternal depression and child psychopathology: a STAR*D-child report. JAMA 2006;295(12):1389-1398. [PubMed: 16551710]

45. Weissman MM, Wickramaratne P, Adams P, Wolk S, Verdeli H, Olfson M. Brief screening for family psychiatric history: the family history screen. Arch Gen Psychiatry 2000;57(7):675-682. [PubMed: 10891038]

46. Weissman MM, Wickramaratne P, Nomura Y, Warner V, Verdeli H, Pilowsky DJ, Grillon C, Bruder G. Families at high and low risk for depression: a 3-generation study. Arch Gen Psychiatry 2005;62(1):29-36. [PubMed: 15630070] 


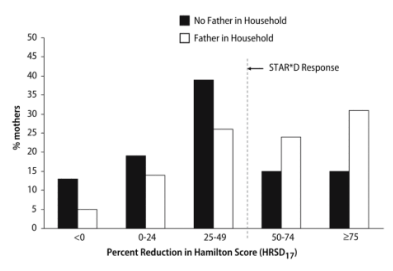

Fig. 1.

Percent of mothers responding to treatment. Single mothers are shown in the gray columns, and mothers residing with a father are shown in white. The response level indicates the percent decrease of baseline symptoms on the $\mathrm{HAMD}_{17}$ scale from the baseline to the 3month evaluation. The " $<0$ " category represents mothers whose symptoms increased over the 3 months. A successful response was defined a priori by STAR*D as a $50 \%$ or greater reduction in symptoms. Based on these criteria, $52 \%$ of mothers living in dual-parent households, but only $28 \%$ of single mothers, successfully responded to treatment $(P=$ $0.009)$. The rates for full remission of symptoms were $43 \%$ and $20 \%$ respectively $(P=$ $0.013)$. Change in maternal depression severity in relation to father's presence 
Table 1

Maternal and child baseline characteristics $(N=111)$

\begin{tabular}{|c|c|c|c|}
\hline & Dual-parent households $(N=61)$ & Single mother households $(N=50)$ & Test statistic, $P$ value ${ }^{i}$ \\
\hline \multicolumn{4}{|l|}{ Mothers } \\
\hline Demographics & $N(\%)$ & $N(\%)$ & \\
\hline White $^{a}$ & $28(46)$ & $15(30)$ & $\chi^{2}=2.2, P=0.13$ \\
\hline Household income $<$ US $\$ 15,000$ & $8(13)$ & $18(39)$ & $\chi^{2}=9.1, P=0.003$ \\
\hline College degree or higher & $20(33)$ & $8(16)$ & $\chi^{2}=4.1, P=0.04$ \\
\hline Employed full time ${ }^{b}$ & $37(60)$ & $20(40)$ & $\chi^{2}=4.1, P=0.04$ \\
\hline \multirow[t]{2}{*}{ Receiving public assistance } & $10(16)$ & $21(44)$ & $\chi^{2}=4.7, P=0.03$ \\
\hline & Mean $(S D)$ & $\operatorname{Mean}(S D)$ & \\
\hline Age & $37.7(6.1)$ & $38.4(6.5)$ & $t=0.56, P=0.57$ \\
\hline $\mathrm{HAMD}_{17}$ score & $23.1(5.2)$ & $25.9(4.9)$ & $t=2.72, P=0.007$ \\
\hline Number of MDEs & $6.5(10)$ & $8.5(18)$ & $t=0.55, P=0.58$ \\
\hline Age at first onset & $20.5(8.5)$ & $20.8(8.2)$ & $t=0.15, P=0.87$ \\
\hline Yrs since first MDE & $17.5(11.3)$ & $17.1(10.4)$ & $t=0.16, P=0.87$ \\
\hline DSM-IV diagnoses ${ }^{c}$ & $N(\%)$ & $N(\%)$ & \\
\hline Generalized anxiety disorder & $18(30)$ & $10(20)$ & $\chi^{2}=1.3, P=0.26$ \\
\hline Social anxiety disorder & $25(41)$ & $26(53)$ & $\chi^{2}=1.4, P=0.23$ \\
\hline Obsessive compulsive disorder & $7(11)$ & $14(29)$ & $\chi^{2}=4.9, P=0.03$ \\
\hline Panic disorder & $3(5)$ & $8(16)$ & $\chi^{2}=3.8, P=0.051$ \\
\hline Post traumatic stress disorder & $8(13)$ & $12(24)$ & $\chi^{2}=2.4, P=0.13$ \\
\hline Substance use disorder $d$ & $4(6)$ & $8(16)$ & $\chi^{2}=2.5, P=0.11$ \\
\hline Social functioninge & Mean $(S D)$ & Mean $(S D)$ & \\
\hline Primary relationship & $2.4(0.6)$ & $2.6(0.6)$ & $t=0.4, P=0.71$ \\
\hline Parenting & $1.9(0.6)$ & $1.9(9.7)$ & $t=0.15, P=0.88$ \\
\hline Work role & $1.8(0.6)$ & $2.4(1.1)$ & $t=2.7, P=0.005$ \\
\hline Social/leisure & $2.5(0.7)$ & $3.0(0.6)$ & $t=3.6, P=0.0005$ \\
\hline Family unit & $2.4(0.9)$ & $2.4(1.3)$ & $t=0.04, P=0.97$ \\
\hline Treatment setting $f$ & $N(\%)$ & $N(\%)$ & \\
\hline Psychiatric outpatient care & $28(46)$ & $15(30)$ & $\chi^{2}=2.9, P=0.08$ \\
\hline \multicolumn{4}{|l|}{ Children } \\
\hline \multirow{3}{*}{ Female } & $N(\%)$ & $N(\%)$ & \\
\hline & $36(59)$ & $25(50)$ & $\chi^{2}=0.9, P=0.34$ \\
\hline & Mean $(S D)$ & Mean $(S D)$ & \\
\hline Age & $11.9(2.5)$ & $11.3(2.9)$ & $t=1.0, P=0.30$ \\
\hline DSM-IV diagnoses ${ }^{g}$ & $N(\%)$ & $N(\%)$ & \\
\hline Any diagnosis & $17(27)$ & $20(40)$ & $\chi^{2}=1.5, P=0.22$ \\
\hline Any depressive disorder & $5(8)$ & $7(14)$ & $\chi^{2}=0.8, P=0.35$ \\
\hline
\end{tabular}




\begin{tabular}{clll}
\hline & Dual-parent households $(\boldsymbol{N}=\mathbf{6 1})$ & Single mother households $(\boldsymbol{N}=\mathbf{5 0})$ & Test statistic, $\boldsymbol{P}$ value $^{\boldsymbol{i}}$ \\
\hline Any anxiety disorder & $8(14)$ & $9(18)$ & $\chi^{2}=0.4, P=0.52$ \\
Any disruptive behavior disorder & $8(14)$ & $12(24)$ & $\chi^{2}=2.0, P=0.16$ \\
& Mean $(S D)$ & Mean $(S D)$ & $t=1.7, P=0.09$ \\
\hline
\end{tabular}

Ns vary due to missing data

${ }^{a}$ Non Hispanic. The reference category included Non-Hispanic Black $(N=44)$, Hispanic $(N=19)$, Asian $(N=2)$, Native American $(N=2)$ and Hawaiian or Pacific Islander $(N=1)$

${ }^{b}$ If part time employment was included, $70 \%$ of mothers with fathers present in the household, and $56 \%$ of single mothers reported working $(P=$ $0.11)$

${ }^{c}$ Based on the Psychiatric Diagnostic Screening Questionnaire (PDSQ)

$d_{\text {Includes drug or alcohol abuse or dependence }}$

${ }^{e}$ Based on the Social Adjustment Scale-Self Report (SAS-SR). Higher scores are indicative of greater social impairment

$f_{\text {Treatment setting included self-referred psychiatric or primary outpatient care }}$

${ }^{g}$ Based on the schedule for affective disorders, present and lifetime version, for school age children. Two children had a comorbid depressive and disruptive behavior disorder, 4 had both a depressive and anxiety disorder, and 8 had both an anxiety and a disruptive behavior (there were no significant differences in the number of comorbid conditions between children in single- and two-parent households)

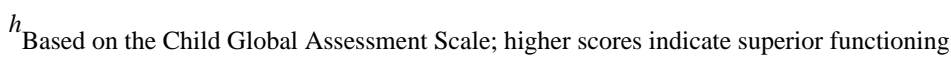

${ }_{P}^{i}$ values are based on chi square tests for categorical variables (Fisher's Exact test was used when $50 \%$ of the cells had expected cell counts less than 5) and $t$-tests for continuous variables 
Table 3

Demographic and clinical characteristics of fathers

\begin{tabular}{|c|c|c|c|}
\hline Fathers $a$ & Dual-parent households $(N=41)$ & Single mother households $(N=50)$ & Test statistic, $P$ value \\
\hline Demographics & $N(\%)$ & $N(\%)$ & \\
\hline White $^{b}$ & $24(59)$ & $14(28)$ & $\chi^{2}=8.6, P=0.003$ \\
\hline College graduate or higher & $9(22)$ & $2(5)$ & $\chi^{2}=5.9, P=0.015$ \\
\hline Employed full time & $27(66)$ & $25(50)$ & $\chi^{2}=2.3, P=0.13$ \\
\hline \multirow[t]{2}{*}{ On public assistance } & $4(10)$ & $1(2)$ & $0.37^{e}$ \\
\hline & Mean $(S D)$ & Mean $(S D)$ & \\
\hline Age & $43.3(7.8)$ & $40.5(7.2)$ & $t=1.7, P=0.09$ \\
\hline Symptoms $c$ & $N(\%)$ & $N(\%)$ & \\
\hline Depressive symptoms & $13(36)$ & $14(45)$ & $\chi^{2}=0.6, P=0.45$ \\
\hline Anxiety symptoms & $13(31)$ & $15(30)$ & $\chi^{2}=0.03, P=0.86$ \\
\hline Substance use problem ${ }^{d}$ & $11(27)$ & $27(67)$ & $\chi^{2}=13.4, P=0.0002$ \\
\hline Ever been arrested or jailed & $7(17)$ & $24(58)$ & $\chi^{2}=15.0, P=0.0001$ \\
\hline
\end{tabular}

${ }^{a}$ Reported by the child's mother, only for biological fathers of the participating child

${ }^{b}$ Non-Hispanic (classification same as that shown in Table 1 for mothers)

${ }^{c}$ Lifetime symptoms, reported by the mother using the family history screen

$d_{\text {Includes drug or alcohol }}$

${ }^{e}$ Based on Fisher's Exact test 


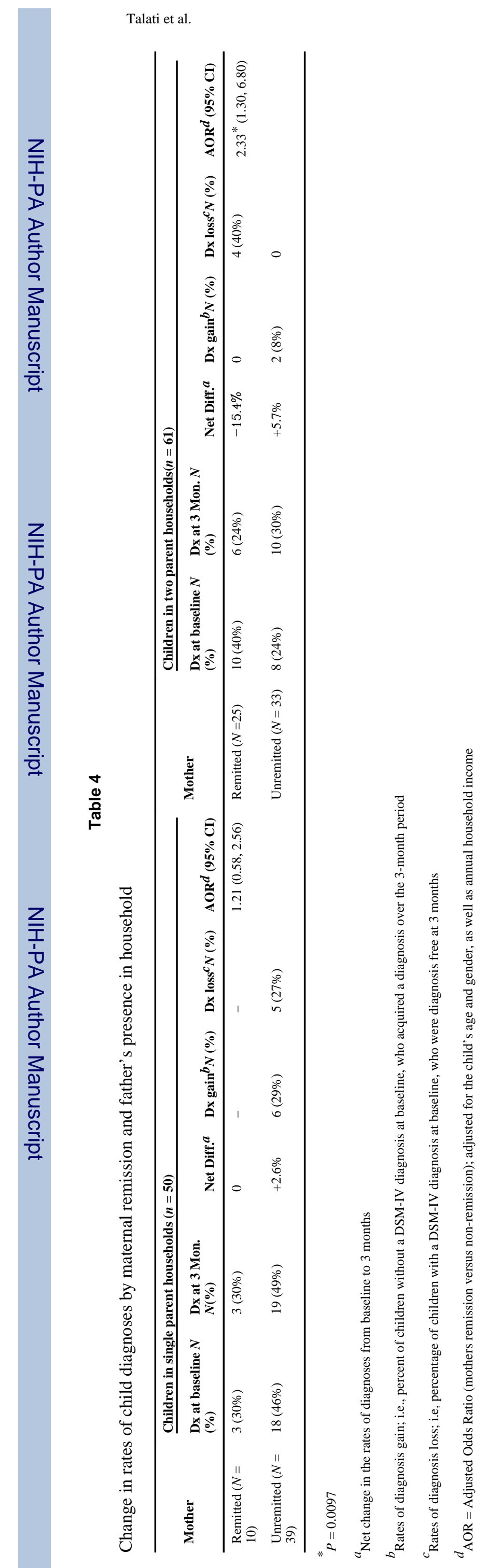

Page 18 